\title{
The cognitive basis of trust \\ The relation between education, cognitive ability, and generalized and political trust
}

\author{
Hooghe, M., Marien, S., De Vroome, T.
}

NOTE: post-print version, August 31, 2012

(post-refereeing, for information see: http://www.sherpa.ac.uk/romeo/issn/0160-2896/)

This article may not exactly replicate the final version published in the journal.

It is not the copy of record.

The definitive version is available online:

Hooghe, M., Marien, S., De Vroome, T. (2012).

The cognitive basis of trust. The relation between education, cognitive ability, and generalized and political trust. Intelligence, 40 (6), 604-613.

http://dx.doi.org/10.1016/j.intell.2012.08.006

\begin{abstract}
Previous research has established convincingly that there is a strong positive relation between educational attainment and trust. There is less agreement however, about the precise determinants of this relation. In this article, we assess how education is related to generalized and political trust, controlling for cognitive ability and occupational prestige, based on the results of the representative NELLS population survey in the Netherlands $(n=1,931)$. The analysis confirms that education is strongly related to trust, but most of this association can be explained by the intermediary mechanisms of cognitive ability and the occupational prestige associated with the level of educational attainment. We close with some observations on how the remaining direct relation between education and trust could be explained.
\end{abstract}

Keywords: education, political trust, generalized trust, cognitive ability, structural equation modeling, the Netherlands

\section{Highlights:}

Cognitive ability $(\mathrm{g})$ is strongly associated with both political trust and with generalized trust. Education is directly related to trust, controlling for cognitive ability and occupational prestige. 
Trust is an important social resource. Within the literature there is a general consensus that trust allows actors to overcome collective action problems and to reach common goals in a more effective manner (Ostrom, 1990; Putnam, 1993; Tavits, 2006). This finding renders it all the more important to arrive at a better understanding of the origins of trust: how and why is this attitude developed and why is it distributed unevenly, both within and between societies? In most of the research, it has been shown that education almost universally is the most important covariate of trust: those with higher education levels are more trusting than those with lower educational credentials (Nannestad, 2008; Borgonovi 2012). There is no consensus, however, on the question how this strong relationship can be explained.

One line of research points to intelligence as the main underlying mechanism. If trust depends on an assessment of how others will deal with the interests of the actor, intelligence allows actors to determine more successfully the motivations of other actors one encounters and interacts with (Yamagishi, 2001; Yamagishi, Kikuchi \& Kosugi, 1999; Sturgis, Read \& Allum, 2010, p. 52). Intelligence can be seen as an important resource in the effort to make sense of the signals that are being sent out with regard to potential defection or untrustworthy behavior (Bacharach \& Gambetta, 2001) and especially social intelligence is claimed to be very important in this regard (Sturgis, Read \& Allum, 2010).

A related possible explanation mentioned in the literature states that trust can be the result of a rational process. Rational actors are able to develop the insight that trusting relations are necessary if they want to achieve their goals in society in a cooperative relationship with others (Gambetta, 1988, pp. 228-234). It can be assumed that those with higher levels of intelligence will have a stronger capacity to develop this insight than those with lower levels of intelligence. Just as Kierkegaard already famously argued about faith, the assumption then would be that those with high levels of cognitive ability opt for the 'leap into trust': even if they know that occasionally they will be disappointed in the behavior of some of their fellow-citizens, following rational insights they are convinced that trust is the only possible means to ensure collective action (Hollis, 1998). Previous studies - mainly based on UK data - indeed show a positive relation between intelligence and generalized and political trust (Yamagishi, 2001; Yamagishi, Kikuchi \& Kosugi, 1999; Sturgis, Read \& Allum, 2010, p. 52; Schoon \& Cheng, 2011; Schoon et al., 2010). In this line of reasoning, Deary, Batty and Gale (2008, p. 1) stated: "bright children become enlightened adults".

Next to this assumed cognitive mechanism, other authors have highlighted the importance of education as a social sorting mechanism (Nie, Junn \& Stehlik-Barry, 1996). The privileged position of the higher educated will render it easier for them to express trust in 
fellow-citizens and in the political system (Newton, 1997). Not only do they understand the cultural codes governing the symbolic order and the interaction within society, their privileged position also implies they are more resistant against the effects of deceit and defection (Hooghe, 2007; Newton, 2007). This strong correlation between social position and trust level can also help us explain why there is a high level of intergenerational transmission in trust levels (Uslaner, 2008), although this inheritability has not been confirmed in all research (Dinesen \& Hooghe, 2010). Applying this logic allows us to assume that education is not directly related to trust, but rather indirectly because it provides access to privileged positions in society. A complication in this line of research is that we can assume that both mechanisms are interrelated, as those with high levels of intelligence could be expected to gain access to more prestigious social positions. While the cognitive and the social sorting mechanism clearly are not incompatible, it is important to try to disentangle both mechanisms in order to arrive at a better insight in the development of trust.

In this article we investigate these suggested pathways mediating the relation between education and trust. The main dependent variable in the analysis is trust, but a number of forms of trust should be distinguished (Newton \& Zmerli, 2011). Generalized trust refers to the trust expressed in other people, and it is generally assumed to be a rather stable personality characteristic (Uslaner, 2002). Political trust is based on a perception of the trustworthiness of the political system. This evaluation is strongly based on knowledge and the information people have gathered, and the knowledge-based nature of trust is strongly emphasized in the political trust literature (Hardin, 1999; Hooghe, 2011). Moreover, the entities we are dealing with when investigating political trust are generally not open for immediate observations and experiences. Most citizens will never have a face to face encounter with "politics" or with the "European Union". Generalised trust, on the other hand, relates to day-to-day interactions on the street, in shops or at work. It requires less abstract reasoning to arrive at the conclusion that most people one meets can be trusted (or not). Hence, expressing political trust requires more abstract reasoning than expressing generalized trust. Consequently, distinguishing both forms of trust is not just necessary for empirical reasons of measurement validity, it also allows us to refine the analysis, as we expect that the cognitive mechanism is stronger for political trust than for generalized trust.

Within the literature, there is a strong and ongoing debate about the way intelligence should be measured (Davidson \& Kemp, 2011). As this kind of population surveys depend on voluntary participation, almost self-evidently the tests should be kept very short. As far as we know there is not a general population survey available that could include the same lengthy 
intelligence tests that can be used in the lab context or when conducting specific tests within schools. While ideally one would have liked the inclusion of a test of social intelligence, it has to be noted that such a test that is also applicable outside of the laboratory currently is simply not available (Sturgis, Read \& Allum, 2010, p. 48; Kihlstrom \& Cantor, 2011). In line with previous research, we therefore use conventional linguistic and mathematical ability tests that are suitable to be included in population surveys that depend on voluntary participation of respondents (Sturgis, Read \& Allum, 2010; Heaven, Ciarrochi and Leeson, 2011).The aim of the present study is to determine whether the observed positive association between education level and trust is mediated by cognitive ability, by the occupational prestige of the respondent, or whether there remains a direct association between education and trust, controlling for these intervening variables. For a graphic representation of the pathways between education and trust, we refer the reader to Figure 1.

Our study adds to previous research in a number of ways. We use recent data from a different social context than the British context namely from a high trusting society: the Netherlands. Previous research is predominantly based on UK based evidence. As Schoon and Cheng (2010, p. 629) point out: the British context is a particular context characterized by lower levels of trust than in several other countries and by a liberal welfare state in which individual rights and responsibilities are emphasized more strongly than collective provisions. It has been shown that in the UK socio-economic status has a stronger stratification impact than in societies that invest more heavily in redistribution (Breen \& Jonsson, 2005). We rely on a large-scale representative cross-sectional survey. We rely on cognitive ability measured among adults after they obtained education rather than cognitive ability at the moment of childhood. While it is valuable to investigate the long-term effects of cognitive ability measured during childhood observations, the cross-sectional data allows us to measure cognitive ability at the moment of the trust measurement. We also include control variables like age and gender, as previous research has shown age and gender differences in levels of trust (Newton \& Zmerli, 2011).

\section{Data and Methods}

\section{Data}

We use data from the first wave of the Netherlands Longitudinal Lifecourse Study (NELLS), which was conducted in 2009 and included a sample of more than 2,000 native majority members in the Netherlands (De Graaf, Kalmijn, Kraaykamp \& Monden, 2010a). A large 
number of first and second generation immigrants were also included in the original sample, because they were intentionally oversampled. We do not include these respondents in our present study, however, since especially the linguistic ability test (only in Dutch) most likely is biased against these minority groups. ${ }^{1}$ In collecting the data, a random sample of 35 municipalities was selected, stratified by region and degree of urbanization. The four largest cities in the Netherlands were also included. Respondents were then randomly selected from the population registry, based on age (range 14 to 45 years), country of birth and parents' country of birth.

Both face-to-face interviews and a self-administered questionnaire were used. The response rate was 56 percent, which is average for this type of survey in the Netherlands (De Graaf et al., 2010b). The response rate is calculated by dividing the number of (complete plus partial) interviews by a relevant base sample that excludes ineligible cases and cases for which the name and address provided by the municipality were incorrect (about $7 \%$ of the initial sample).

The sample originally includes 2,556 native Dutch respondents. Because our study partly focuses on the relation between education level and occupational prestige, and this information is not available or meaningful for those who still study, we exclude respondents who are younger than 18 and respondents who are still in the education system, reducing the sample size to $2,038 .^{2}$ Furthermore, 66 respondents did not fill out the self-completion part of the survey, containing several key items for our study, and another 41 respondents had missing values on one or more of the measures used. Because the number of respondents with missing values is rather limited (about 5\%), and because, for the respondents who did not fill out the self-completion questionnaire, too much information is missing to impute values properly, we used listwise deletion of cases with missing values. As a result, the present analysis includes 1,931 respondents.

\section{Measurements}

\section{Dependent variables}

Generalized trust was measured with the following three statements, to which respondents could answer on a five-point scale: 'You can't be too careful in dealing with people', 'If you trust too easily, people will take advantage of you', and 'You will often be cheated when you help others'. This is the standard measurement scale in population surveys 
in Europe, and the scale has been shown to be cross-culturally equivalent (Reeskens \& Hooghe, 2008). Analysis shows that the scale reliability is acceptable (Cronbach's alpha= .74).

Political trust was measured with the question: 'Could you indicate how much trust you have in the following institutions: a. politics, b. the government, c. the European Union, and $\mathrm{d}$. the police and justice department?', to which respondents could answer on a four-point scale. The four items constitute a reliable scale (Cronbach's alpha $=.83$ ). This scale is routinely used to measure political trust and proves to be a valid one-dimensional scale and cross-culturally equivalent (Marien, 2011).

Independent variables

Education is measured on a six-point scale, ranging from no education, through primary, lower secondary, higher secondary and lower tertiary, to higher tertiary education. We have excluded respondents who were still following education from our main analysis, because the occupational prestige mechanism that we want to investigate does not quite apply to them (yet).

The cognitive ability measurement was based on two tests. Linguistic ability was measured with nine items on which respondents were required to identify the synonym of a given word. Mathematical ability was measured with five items on which respondents were required to logically complete a sequence of numbers. For the items measuring linguistic ability, respondents were required to select the correct answer among five alternatives. For the items measuring mathematical ability, respondents were required to select the correct answer among four alternatives. An example of the linguistic ability items (the item that loads most strongly on the latent factor) is: 'which description fits best the word 'abrupt'?', to which respondents could answer a. heavy, b. distinct, c. sudden, d. vain, e. insufficient, or f. 'don't know'. An example of the mathematical ability items is: 'which number logically completes the sequence $21,20,18,15,11$, ?', to which respondents could answer a. '26', b. '17', c. ' 8 ', d. '6', or e. 'don't know'. Both scales have acceptable reliability (Linguistic: Cronbach's alpha $=.70$, Mathematical: Cronbach's alpha=.71). The Pearson correlation between the two scales is .40 .

For occupational prestige, we use the 'standard international socioeconomic index of occupational status (ISEI)', ranging from 16 (in our sample 22) to 88 (Ganzeboom et al., 1992). We use a control variable indicating whether respondents are employed, and 
unemployed respondents were given the mean score of the employed respondents on the variable for occupational prestige, in order to avoid any bias. ${ }^{3}$

To assess whether respondents have financial difficulties, they were asked 'Have you, over the course of the last three months, had to deal with the following: (a) not being able to replace broken equipment, (b) having to borrow money for essential expenses, (c) falling behind on regular expenses, (d) being visited by a bailiff, (e) having difficulty making ends meet'. The reliability of the scale is reasonable (Cronbach's alpha=.67). Finally, we include gender and age as control variables as previous research has shown that trust levels are higher among men and among older people (Newton \& Zmerli, 2011).

\section{Methods}

Following preliminary analyses in SPSS 19, MPLUS 6 was used to analyze the data. All models were fitted by a robust weighted least squares estimator, with which probit regressions are estimated for the categorical dependent variables (i.e. factor indicators), and linear regressions are estimated for the continuous dependent variables (Múthen \& Múthen, 2010, p.3). As suggested by Kline (2010), we use a two-step approach for our structural equation models: we first build and test a measurement model before testing a model that includes the hypothesized relations.

Confirmatory factor analysis was used to determine whether the covariance structure is consistent with the theoretical model. The fit of the measurement model proved to be adequate $\left(\mathrm{Chi}^{2}=619.4, \mathrm{df}=291, \mathrm{p}<.001 ; \mathrm{CFI}=.969, \quad \mathrm{RMSEA}=.024\right)$. All items load significantly on their respective latent constructs. Inspection of the standardized regression weights and r-squares indicated that one of the items measuring linguistic ability did not load very strongly on its latent factor $\left(\beta<.40 ; \mathrm{r}^{2}<.20\right)$. Because the loading is significant, however, and because we do not have a substantive reason to remove the item, it was left in place.

We use cognitive ability as a second-order factor which is measured by the indicators linguistic ability and mathematical ability, which are itself first-order latent factors. We have constrained the regression coefficient of cognitive ability on linguistic ability to one for model identification. It should be noted that the linguistic ability factor loads more strongly on $\mathrm{g}$ ( $\beta=.88$ in the measurement model) than the mathematical ability factor $(\beta=.67$ in the measurement model). ${ }^{4}$ A graphical representation of the measurement model can be found in the appendix (Figure A.1). 
After having established a satisfactory measurement model, we have added the observed predictors (i.e. education level and occupational prestige, and the control variables) and hypothesized relations. The fit of our initial structural model was already reasonably good $\left(\mathrm{Chi}^{2}=1408.7, \mathrm{df}=413, \mathrm{p}<.001 ; \mathrm{CFI}=.901, \mathrm{RMSEA}=.035\right)$. We used the modification indices provided by MPLUS, however, to detect whether the model still contained severe misspecifications. Also because it makes sense substantively, we include age as a predictor of Cognitive ability, because this clearly improves the model fit and because one can expect that cognitive ability (especially vocabulary) increase during the life cycle as well as with higher education. The resulting final model has satisfactory model fit $\left(\mathrm{Chi}^{2}=1161.2, \mathrm{df}=412, \mathrm{p}<.001\right.$; $\mathrm{CFI}=.926, \mathrm{RMSEA}=.031)$.

\section{Results}

First, we present an overview of the distribution of the variables (Table 1). The descriptive statistics of the latent constructs in Table 1 are based on scales that we have computed in SPSS. The mean level of generalized trust is just above the midpoint of the scale, while the mean level of political trust is somewhat below the midpoint. It should be noted that most of the respondents in the sample are employed (more than 90 percent). It is also noteworthy that fewer respondents report financial problems than could be expected given the Dutch population figures on poverty.

- Table 1 about here -

Next, we present the results of our structural equation models, which allow us to investigate the direct and indirect relations between education on the one hand and generalized trust and political trust on the other hand. Figure 1 presents an overview of our SEM model, including the standardized regression weights for the structural part of the model. In Table 2, we give an overview of the total, direct, total indirect and specific indirect relations between education and generalized and political trust. Additionally, the unstandardized and standardized regression weights for all relations in our final model are included in the appendix (Table A.1 and Table A.2), as are the residual variances (Table A.3) ${ }^{5}$

- Figure 1 about here - 
From Figure 1, it becomes clear that there are positive direct relations between education on the one hand and generalized and political trust on the other (regression weights for the associations are $\beta=.10$ for generalized trust and $\beta=.13$ for political trust). The results in Figure 1 however mostly suggest the importance of the intermediary mechanisms, but despite the inclusion of these variables, we still observe quite robust direct relations between education and trust levels. Moreover, a $\mathrm{Chi}^{2}$ difference test indicates that a model excluding the direct relations between education and trust fits the data more poorly than the model including the direct relations $\left(\mathrm{Chi}^{2}=16.7, \mathrm{df}=2, \mathrm{p}<.001\right)$. This implies that while the intermediary variables that we discussed in the introduction might capture most of the relation between education and trust, there is still a part of the relation that is not mediated in this manner.

When looking at the standardized regression weights in Figure 1, it is clear that the argument for a cognitive mechanism receives support. There is a strong relation between education level and cognitive ability $(\beta=.54)$. Cognitive ability, in turn, is positively related to generalized and political trust ( $\beta=.30$ for generalized trust and $\beta=.21$ for political trust).

The results provide strong support for the social sorting (economic) mechanism, as can be concluded from results in Figure 1. We find that education level is positively related to occupational prestige $(\beta=.47)$ and negatively related to having financial problems $(\beta=-.23)$. Subsequently, occupational prestige is positively related to trust levels $(\beta=.14$ for generalized trust and $\beta=.11$ for political trust), and having financial problems is negatively related to trust levels ( $\beta=-.18$ for generalized trust and $\beta=-.20$ for political trust).

- Table 2 about here -

The results in Table 2 further illustrate the magnitude of the direct and indirect relations between education and trust. All hypothesized indirect relations prove to be significant. Looking at the standardized regression weights in Table 2, it is noteworthy that the direct relation between education and generalized trust $(\beta=.10)$ still amounts to more than a quarter of the total relation $(\beta=.37)$, and that the direct relation between education and political trust $(\beta=.13)$ is responsible for more than one-third of the total relation $(\beta=.34)$. All in all, the model explains about 27 percent of the variance in generalized social trust and 21 percent of the variance in political trust, as becomes apparent from the R-squares listed in appendix Table A.1. 


\section{Discussion}

It is an almost universal finding that there is a strong and positive relation between education level and trust, and the current analysis simply confirms this finding. In contrast to previous studies, however, we have tried to disentangle the various pathways that could help us explain this relation.

Newton (1997) has famously remarked that trust is a privilege of the 'winners in society', as those who have a higher socio-economic status will find it easier to express trust in the social arrangements that have provided them with this high status. Indeed, this claim is supported in the current analysis, as we observe a positive relation between occupational prestige, not having financing problems and trust. It has to be noted, however, that the combined indirect effect of this mechanism is not all that impressive with regard to generalized trust, where intelligence clearly is more important. The relation between education and trust clearly cannot be reduced to the fact that higher education levels in general give access to more privileged positions in society. While this sorting approach to the development of trust provides some information to the puzzle, it is also clear that this is not the main contribution of education.

A stronger indirect relation (at least for generalized trust) was found by including intelligence as an intermediary mechanism. The claim that trust is a rational response if we want to achieve collective action results in our environment is indeed supported by our findings. Those who score high on these tests are more likely to express trust, not only in their fellow-citizens but also in the political system. The results of the current analysis therefore clearly lend support there is a cognitive basis for trust, even controlling for education level, occupational prestige, financial situation, age and gender. More than one third of the total relation between education and generalized trust is mediated by intelligence and this suggests that intelligence renders it easier to predict the likely trustworthy or untrustworthy behavior of others. Contrary to expectations, cognitive ability has a larger effect on generalized trust than on political trust.

What is striking in the structural equation models, finally, is that despite all the controls for intermediary mechanisms, we still find a direct relation between education and trust. For generalized and political trust, this relation is respectively ca .10 and .13 (standardized). We do not have all that much information on how to explain this direct relation. The only thing we can say is that this relation is not mediated by cognitive ability or 
by occupational prestige, since these were controlled for. So how can we explain this direct association between education and trust?

First, we have to acknowledge that a reverse causal logic is just as likely. Those who have trust in others and in the system are more likely to prosper in the education system, and therefore they will end up with high educational credentials. Pupils with a distrusting attitude more likely will not develop an academic orientation and in the end this will lead to lower education levels.

Second, it has to be noted that education is not just about acquiring cognitive abilities, but also can be seen as a social and therefore socializing experience. The respondents who have finished a university degree will have spent almost twenty years of their life in the education system, and most likely this is a period of very intense interactions, not only with their teachers but also with their peers in class. Classes are a very specific interaction context because although some competition and tensions might be involved, classes in general share a common goal (Parsons, 1959). So those who have been in the school system for a longer period, and who have been successful in it, simply might have been exposed more intensively to experiences that enhance trust levels.

Third, it would make sense to look at the content of education efforts. Trust typically is a pro-social attitude that is actively encouraged by the school system and the values of teachers (Van Maele \& Van Houtte, 2011). Apparently these values are also being transmitted in some way or another to pupils, and thus to adults with high education levels. How this value transfer actually takes place, however, is again a topic that merits further research attention.

Strengths of the current study include the study of cognitive ability and trust beyond the UK context; the large, representative sample of the Dutch population; the inclusion of respondents of different age; the high validity of the trust scales; and the comparison between political and generalized trust. The study's limitations include the cognitive ability measurements. While the measurement characteristics of both the linguistic and the mathematic ability test strongly suggest a valid measurement, the cognitive tests were rather limited as is unavoidable in population surveys. The data also apply to one country's political system. However, these data might have wider relevance beyond the Netherlands to other similar welfare states. Given the cross-sectional nature of the data, the data do not allow making causal claims. 


\section{References}

Bacharach, M. \& Gambetta, D. (2001). Trust in signs in K. Cook (Ed.), Trust in Society. (pp. 148-184). New York: Russell Sage Foundation.

Bobo, L. \& Licari, F.C. (1989). Education and political tolerance: testing the effects of cognitive sophistication and target group affect. Public Opinion Quarterly, 53(3), 285308 .

Borgonovi, F. (2012). The relationship between education and levels of trust and tolerance in Europe. British Journal of Sociology, 63(1), 146-167.

Breen, R. \& J. Jonsson (2005). Inequality of opportunity in comparative perspective. Annual Review of Sociology, 31, 223-243.

Davidson, J. \& I. Kemp (2011). Contemporary models of intelligence, pp. 58-83 in R. Sternberg \& S.B. Kaufman (eds.), The Cambridge Handbook of Intelligence. Cambridge: Cambridge University Press.

Deary, I.J., Batty, D.G., Gale, C.R. (2008). Bright Children Become Enlightened Adults, Psychological Science, 19(1), 1-21.

De Graaf, P.M., Kalmijn, M., Kraaykamp, G., Monden, C.W.S. (2010a). The NEtherlands Longitudinal Lifecourse Study (NELLS Wave 1). Dataset. Tilburg University and Radboud University Nijmegen, Netherlands.

De Graaf, P.M., Kalmijn, M., Kraaykamp, G., Monden, C.W.S. (2010b). Design and content of the NEtherlands Longitudinal Lifecourse Study (NELLS). Research report. Tilburg University and Radboud University Nijmegen, Netherlands.

Dinesen, P.T. \& Hooghe, M. (2010). When in Rome, do as the Romans do. The acculturation of generalized trust among immigrants in Europe. International Migration Review, 44(3), 697-727.

Gambetta, D. (1988). Can we trust Trust, pp. 213-238 in D. Gambetta (ed.), Trust. Making and Breaking Cooperative Relations. Oxford: Blackwell.

Ganzeboom, H. B. G., et al. (1992). A standard international socio-economic index of occupational status, Social Science Research, 21(1), 1-56.

Hardin, R. (1999). Do we want trust in government?, pp. 22-41 in Mark Warren (ed.), Democracy and Trust. Cambridge: Cambridge University Press.

Heaven, P.C.L., Ciarrochi, J. \& Leeson, P. (2011). Cognitive Ability, Right-Wing Authoritarianism, and Social Dominance Orientation; A Five-Year Longitudinal Study Among Adolescents, Intelligence, 15-21.

Hollis, M. (1998). Trust within reason. Cambridge: Cambridge University Press.

Hooghe, M. (2007). Social capital and diversity. Generalized trust, social cohesion and regimes of diversity. Canadian Journal of Political Science, 40(3), 709-732.

Hooghe, M. (2011). Why there there is basically only one form of political trust. British Journal of Politics and International Relations, 13(2), 269-275.

Kihlstrom, J. \& N. Cantor (2011). Social intelligence, pp. 564-581 in R. Sternberg \& S.B. Kaufman (eds.), The Cambridge Handbook of Intelligence. Cambridge: Cambridge University Press

Kline, R.B. (2010). Principles and Practice of Structural Equation Modeling, Third Edition. New York: Guilford Press.

Krosnick, J. A. \& Alwin, D. F. (1987). An evaluation of a cognitive theory of response order effects in survey measurement. Public Opinion Quarterly, 51(2), 201-219.

Luhmann, N. (1968). Vertrauen. Ein Mechanismus der Reduktion sozialer Komplexität. Stuttgart: Enke.

Marien, S. (2011). Measuring political trust across time and space. In M. Hooghe, S. Zmerli (Eds.), Political Trust. Why Context Matters, (pp. 13-46). Colchester: ECPR Press. 
Múthen, L. K. \& Múthen, B.O. (2010). Mplus User's Guide. Sixth Edition. Los Angeles: Múthen \& Múthen.

Nannestad, P. (2008). What have we learned about generalized trust, if anything? Annual Review of Political Science, 11, 413-436.

Newton, K. (1997). Social capital and democracy. American Behavioral Scientist 40, 575586.

Newton, K. (2007). Social and political trust. In R. Dalton, \& H.-D. Klingemann (Eds.), Oxford handbook of political behaviour (pp. 342-361). Oxford: Oxford University Press.

Newton, K., \& Zmerli, S. (2011). Three forms of trust and three models of their association: Relations between particular social trust, general social trust and political trust, European Political Science Review, 3(2), 169-200.

Nie, N., Junn, J. \& K. Stehlik-Barry (1996). Education and Democratic Citizenship in America. Chicago: University of Chicago Press.

Ostrom, E. (1990). Governing the commons. Cambridge: Cambridge University Press.

Parsons, T. (1959). The School Class as a Social System. Harvard Educational Review, 29(4), 297-318.

Putnam, R. (1993). Making Democracy Work. Civic Traditions in Modern Italy. Princeton: Princeton University Press.

Reeskens, T. \& Hooghe, M. (2008). Cross-Cultural Measurement Equivalence of Generalized Trust. Social Indicators Research, 85(3), 515-532

Schoon, I. \& H. Cheng (2011). Determinants of political trust. A life-long learning model. Developmental Psychology, 47(3), 619-631.

Schoon, I., Cheng, H., Gale, C., Batty, D. \& Deary, I. (2010). Social status, cognitive ability, and educational attainment as predictors of liberal social attitudes and political trust. Intelligence, 38(1), 144-150.

Sturgis, P., Read, S. \& N. Allum (2010). Does intelligence foster generalized trust? An empirical test using the UK birth cohort studies, Intelligence, 38(1), 45-54.

Tavits, M. (2006). Making democracy work more? Exploring the linkage between social capital and government performance. Political Research Quarterly, 59, 211-225.

Uslaner, E. (2002). The moral foundation of trust. Cambridge: Cambridge University Press.

Uslaner, E. (2008). 'Where you stand depends upon where your grandparents sat. The inheritability of generalized trust. Public Opinion Quarterly, 72(4), 725-740.

Van Maele, D. \& Van Houtte, M. (2011). Collegial Trust and the Organizational Context of the Teacher Workplace. The Role of a Homogeneous Teachability Culture. American Journal of Education, 117(4), 437-464.

Yamagishi, T., Kikuchi, M. \& Kosugi, M. (1999). Trust, gullibility and social intelligence. Asian Journal of Social Psychology, 2(1), 145-161

Yamagishi, T. (2001). Trust as a form of social intelligence, pp. 121-147 in K. Cook (ed.), Trust in society. New York: Russell Sage Foundation. 
Figure 1

Standardized relations between education, mediators and generalized and political trust

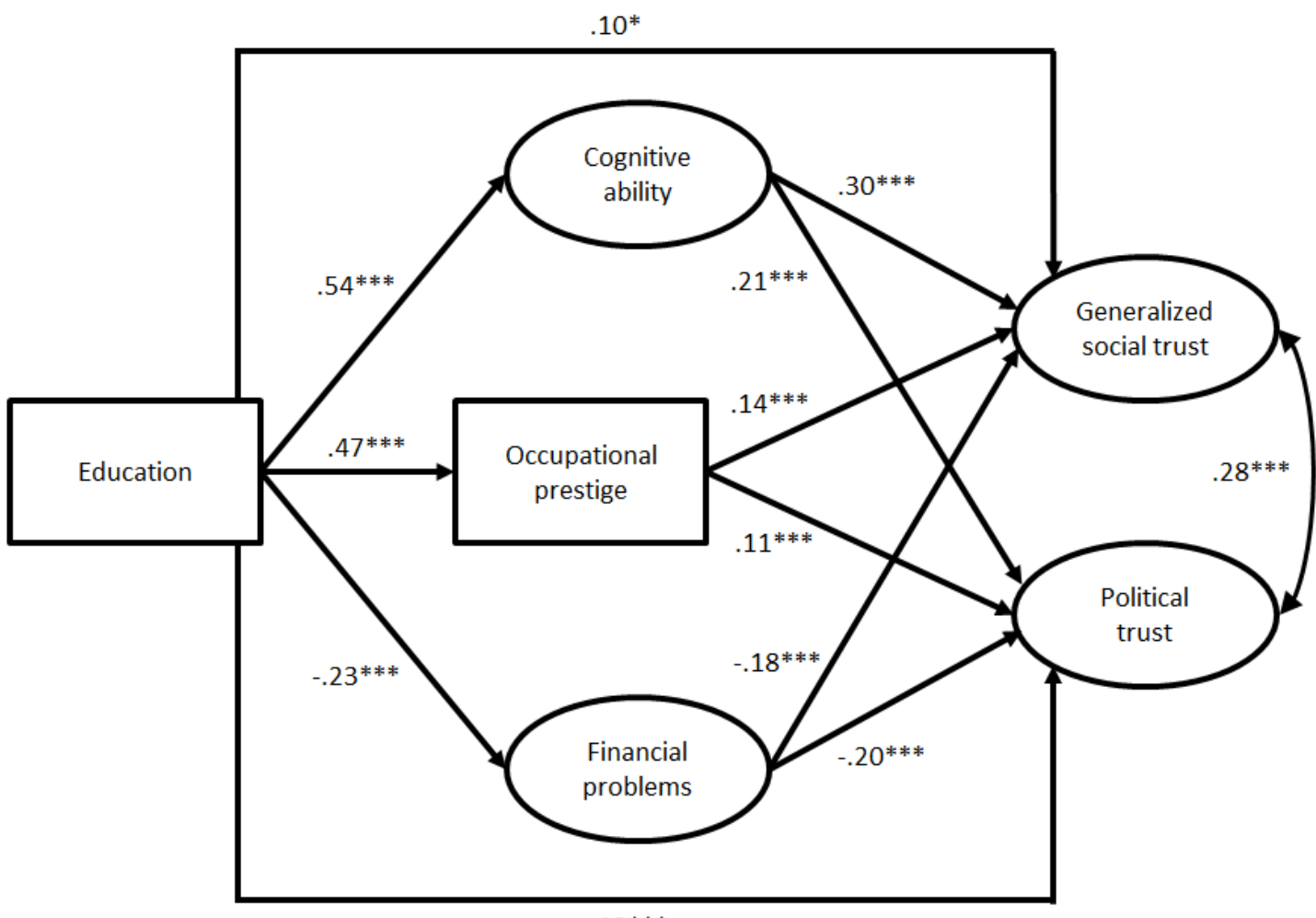

$.13^{* * *}$

Source: NELLS 2009, own calculations. N=1931.

Notes: Entries are standardized regression weights. ${ }^{* * *}: \mathrm{p}<.001, *: \mathrm{p}<.05$. Rectangles represent observed predictors, ovals represent latent factors. Not presented in this figure are the factor items, control variables and residual variances. Please refer to the appendix for these results. 
Table 1

Descriptive statistics of observed and latent variables, with Pearson correlations, $\mathrm{N}=1931$.

\begin{tabular}{|c|c|c|c|c|c|c|c|c|c|c|c|c|c|c|}
\hline Variables & & Range & Mean & SD & 1 & 2 & 3 & 4 & 5 & 6 & 7 & 8 & 9 & 10 \\
\hline & Dependent variables & & & & & & & & & & & & & \\
\hline 1 & Generalized trust & $0-4$ & 2.099 & .705 & - & .346 & .322 & .286 & .179 & .237 & -.166 & .125 & .051 & .099 \\
\hline \multirow[t]{2}{*}{2} & Political trust & $0-3$ & 1.322 & .545 & & - & .326 & .216 & .189 & .210 & -.189 & -.014 & .061 & .131 \\
\hline & Independent variable & & & & & & & & & & & & & \\
\hline \multirow[t]{3}{*}{3} & Education & $0-5$ & 3.138 & 1.045 & & & - & .420 & .320 & .447 & -.182 & .017 & .012 & .208 \\
\hline & Mediators & & & & & & & & & & & & & \\
\hline & Cognitive ability & & & & & & & & & & & & & \\
\hline 4 & Linguistic ability & $0-9$ & 6.720 & 1.933 & & & & - & .402 & .273 & -.114 & .272 & -.002 & .163 \\
\hline 5 & Mathematical ability & $0-5$ & 3.687 & 1.440 & & & & & - & .254 & -.105 & .038 & -.103 & .133 \\
\hline 6 & Occupational prestige & $22-88$ & 49.010 & 14.306 & & & & & & - & -.098 & .056 & -.045 & .001 \\
\hline \multirow[t]{2}{*}{7} & Financial problems & $0-5$ & .416 & .888 & & & & & & & - & -.037 & .010 & -.159 \\
\hline & Control variables & & & & & & & & & & & & & \\
\hline 8 & Age & $18-47$ & 34.695 & 7.245 & & & & & & & & - & .016 & .033 \\
\hline 9 & Female & $0 / 1$ & .545 & & & & & & & & & & - & -.100 \\
\hline 10 & Currently employed & $0 / 1$ & .908 & & & & & & & & & & & - \\
\hline
\end{tabular}

Source: NELLS 2009, own calculations.

Note: To facilitate interpretation, the mean and standard deviation of the latent variables (i.e. generalized trust, political trust, linguistic ability, mathematical ability, and financial problems) are approximated by calculating scales (the average of the items or, in the case of 'linguistic ability', 'mathematical ability', and 'financial problems', the sum of the items). 
Table 2

Direct and indirect relations between education and generalized and political trust

\begin{tabular}{lllllll}
\hline Path & & & B & S.E. & $\boldsymbol{\beta}$ & P \\
\hline Generalized trust & & & & & & \\
Generalized trust & $\leftarrow$ Education & (Total) & .203 & .016 & .367 & $* * *$ \\
Generalized trust & $\leftarrow$ Education & (Direct) & .054 & .021 & .098 & .010 \\
Generalized trust & $\leftarrow$ Education & (Indirect) & .149 & .019 & .269 & $* * *$ \\
Generalized trust & $\leftarrow$ Cognitive ability & $\leftarrow$ Education & .090 & .015 & .164 & $* * *$ \\
Generalized trust & $\leftarrow$ Occupational prestige & $\leftarrow$ Education & .036 & .007 & .065 & $* * *$ \\
Generalized trust & $\leftarrow$ Financial problems & $\leftarrow$ Education & .022 & .006 & .041 & $* * *$ \\
Political trust & & & & & & \\
Political trust & $\leftarrow$ Education & (Total) & .167 & .012 & .340 & $* * *$ \\
Political trust & $\leftarrow$ Education & (Direct) & .065 & .018 & .132 & $* * *$ \\
Political trust & $\leftarrow$ Education & (Indirect) & .102 & .015 & .208 & $* * *$ \\
Political trust & $\leftarrow$ Cognitive ability & $\leftarrow$ Education & .055 & .012 & .112 & $* * *$ \\
Political trust & $\leftarrow$ Occupational prestige & $\leftarrow$ Education & .025 & .006 & .050 & $* * *$ \\
Political trust & $\leftarrow$ Financial problems & $\leftarrow$ Education & .022 & .005 & .046 & $* * *$ \\
\hline
\end{tabular}

Source: NELLS 2009, own calculations. N=1931. ***: $\mathrm{p}<.001$.

Entries are the result of a SEM analysis in MPLUS. Reported are the unstandardized coefficients (B), standard errors (S.E.), standardized coefficients $(\beta)$ and P-values. 


\section{Appendix}

Figure A.1: Measurement model

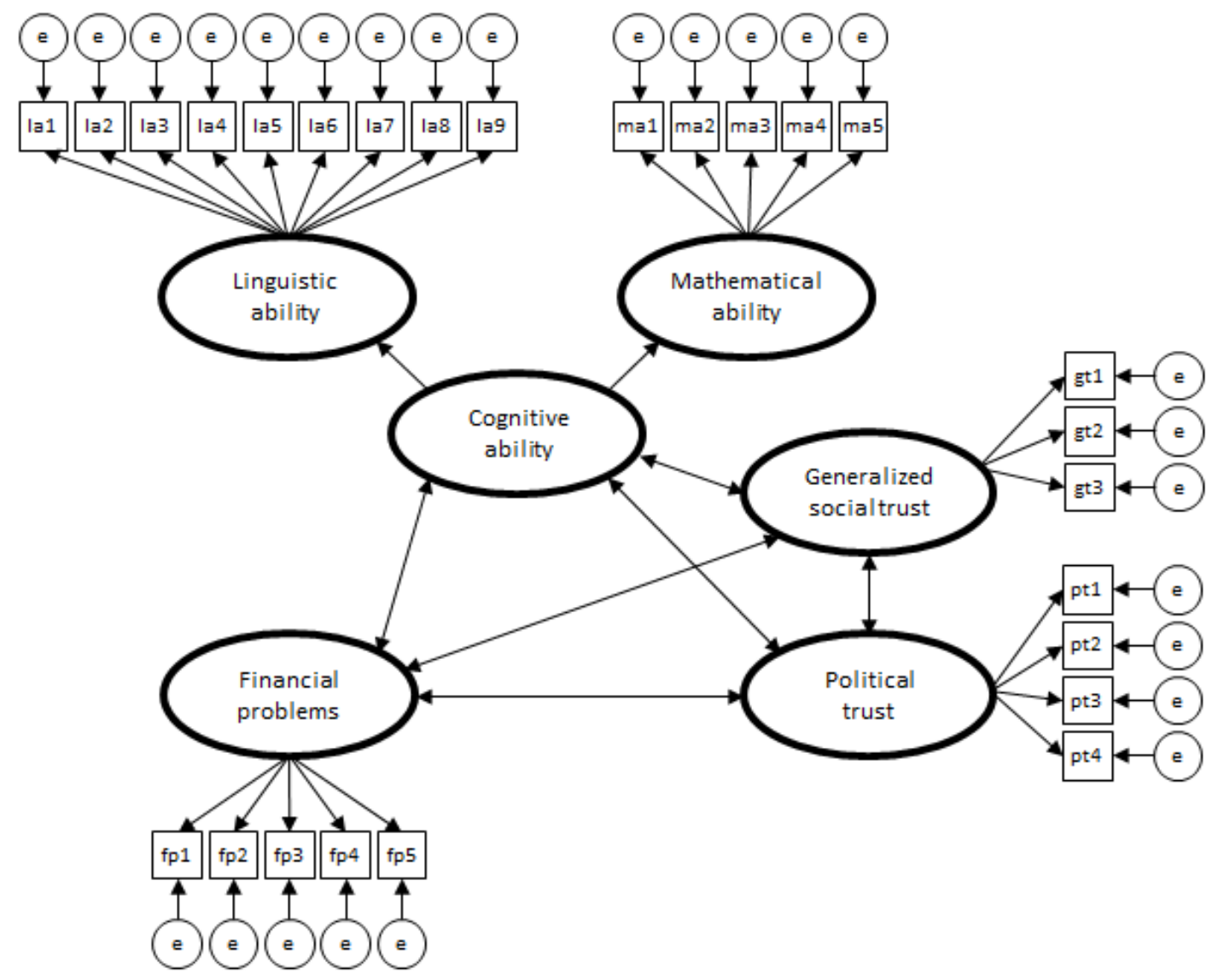

Notes: Rectangles represent observed predictors, ovals represent latent factors. 
Table A.1: Structural relations in final model

\begin{tabular}{|c|c|c|c|c|c|}
\hline Path & & B & S.E. & $\boldsymbol{\beta}$ & $\mathbf{P}$ \\
\hline \multicolumn{6}{|c|}{ Intermediary variables } \\
\hline Cognitive ability & $\leftarrow$ Education & .355 & .026 & .541 & $* * *$ \\
\hline Cognitive ability & $\leftarrow$ Age & .024 & .003 & .258 & $* * *$ \\
\hline Occupational prestige & $\leftarrow$ Education & 6.411 & .250 & .468 & $* * *$ \\
\hline Financial problems & $\leftarrow$ Education & -.162 & .025 & -.226 & $* * *$ \\
\hline \multicolumn{6}{|l|}{ Generalized trust } \\
\hline Generalized Trust & $\leftarrow$ Education & .054 & .021 & .098 & .010 \\
\hline Generalized Trust & $\leftarrow$ Cognitive ability & .255 & .043 & .303 & $* * *$ \\
\hline Generalized Trust & $\leftarrow$ Occupational prestige & .006 & .001 & .139 & $* * *$ \\
\hline Generalized Trust & $\leftarrow$ Financial problems & -.138 & .029 & -.180 & $* * *$ \\
\hline Generalized Trust & $\leftarrow$ Age & .004 & .002 & .054 & .047 \\
\hline Generalized Trust & $\leftarrow$ Female & .063 & .029 & .055 & .029 \\
\hline Generalized Trust & $\leftarrow$ Currently employed & .092 & .048 & .046 & .052 \\
\hline \multicolumn{6}{|l|}{ Political trust } \\
\hline Political Trust & $\leftarrow$ Education & .065 & .018 & .132 & $* * *$ \\
\hline Political Trust & $\leftarrow$ Cognitive ability & .155 & .034 & .208 & $* * *$ \\
\hline Political Trust & $\leftarrow$ Occupational prestige & .004 & .001 & .107 & $* * *$ \\
\hline Political Trust & $\leftarrow$ Financial problems & -.138 & .024 & -.202 & $* * *$ \\
\hline Political Trust & $\leftarrow$ Age & -.005 & .002 & -.074 & .003 \\
\hline Political Trust & $\leftarrow$ Female & .068 & .024 & .066 & .005 \\
\hline Political Trust & $\leftarrow$ Currently employed & .142 & .042 & .080 & .001 \\
\hline \multicolumn{6}{|l|}{ Model fit } \\
\hline $\mathrm{Chi}^{2}$ & & 1161.2 & $* * *$ & & \\
\hline DF & & 412 & & & \\
\hline CFI & & .926 & & & \\
\hline RMSEA & & .031 & & & \\
\hline $\mathrm{R}^{2}$ Generalized trust & & .271 & & & \\
\hline $\mathrm{R}^{2}$ Political trust & & .212 & & & \\
\hline $\mathrm{N}$ & & 1931 & & & \\
\hline
\end{tabular}

Source: NELLS 2009, own calculations. ***: $\mathrm{p}<.001$.

Entries are the result of a SEM analysis in MPLUS. Reported are the unstandardized regression weights (B), standard errors (S.E.), standardized regression weights $(\beta)$ and P-values. $\mathrm{CFI}=$ comparative fit index, $\mathrm{RMSEA}=$ root mean square error of approximation. Not presented in the table is the covariance between generalized trust and political trust $(b=.064 ; \mathrm{se}=.008 ; \beta=.284 ; \mathrm{p}<.001)$, which is specified in the model. 
Table A.2: Measurement part final model

\begin{tabular}{|c|c|c|c|c|c|}
\hline Path & & B & S.E. & $\boldsymbol{\beta}$ & $\mathbf{P}$ \\
\hline Generalized trust - item 1 & $\leftarrow$ Generalized Trust $^{a}$ & 1.000 & & .674 & \\
\hline Generalized trust - item 2 & $\leftarrow$ Generalized Trust & 1.012 & .058 & .636 & $* * *$ \\
\hline Generalized trust - item 3 & $\leftarrow$ Generalized Trust & 1.113 & .066 & .783 & $* * *$ \\
\hline Political trust - item 1 & $\leftarrow$ Political Trust $^{\mathrm{a}}$ & 1.000 & & .801 & \\
\hline Political trust - item 2 & $\leftarrow$ Political Trust & 1.144 & .035 & .882 & $* * *$ \\
\hline Political trust - item 3 & $\leftarrow$ Political Trust & .847 & .033 & .650 & $* * *$ \\
\hline Political trust - item 4 & $\leftarrow$ Political Trust & .886 & .041 & .654 & $* * *$ \\
\hline Linguistic ability - item 1 & $\leftarrow$ Linguistic ability $^{\mathrm{a}}$ & 1.000 & & .668 & \\
\hline Linguistic ability - item 2 & $\leftarrow$ Linguistic ability & 1.195 & .080 & .774 & $* * *$ \\
\hline Linguistic ability - item 3 & $\leftarrow$ Linguistic ability & 1.090 & .070 & .718 & $* * *$ \\
\hline Linguistic ability - item 4 & $\leftarrow$ Linguistic ability & 1.146 & .079 & .749 & $* * *$ \\
\hline Linguistic ability - item 5 & $\leftarrow$ Linguistic ability & .504 & .057 & .357 & $* * *$ \\
\hline Linguistic ability - item 6 & $\leftarrow$ Linguistic ability & 1.083 & .069 & .714 & $* * *$ \\
\hline Linguistic ability - item 7 & $\leftarrow$ Linguistic ability & 1.368 & .092 & .861 & $* * *$ \\
\hline Linguistic ability - item 8 & $\leftarrow$ Linguistic ability & .763 & .056 & .526 & $* * *$ \\
\hline Linguistic ability - item 9 & $\leftarrow$ Linguistic ability & .950 & .068 & .639 & $* * *$ \\
\hline Mathematical ability - item 1 & $\leftarrow$ Mathematical ability $^{a}$ & 1.000 & & .770 & \\
\hline Mathematical ability - item 2 & $\leftarrow$ Mathematical ability & .841 & .044 & .656 & $* * *$ \\
\hline Mathematical ability - item 3 & $\leftarrow$ Mathematical ability & 1.191 & .052 & .901 & $* * *$ \\
\hline Mathematical ability - item 4 & $\leftarrow$ Mathematical ability & .937 & .045 & .726 & $* * *$ \\
\hline Mathematical ability - item 5 & $\leftarrow$ Mathematical ability & 1.034 & .058 & .794 & $* * *$ \\
\hline Linguistic ability & $\leftarrow$ Cognitive ability $^{\mathrm{a}}$ & 1.000 & & .949 & \\
\hline Mathematical ability & $\leftarrow$ Cognitive ability & .749 & .070 & .637 & $* * *$ \\
\hline Financial problems - item 1 & $\leftarrow$ Financial problems $^{\text {a }}$ & 1.000 & & .740 & \\
\hline Financial problems - item 2 & $\leftarrow$ Financial problems & 1.044 & .066 & .772 & $* * *$ \\
\hline Financial problems - item 3 & $\leftarrow$ Financial problems & 1.235 & .069 & .908 & $* * *$ \\
\hline Financial problems - item 4 & $\leftarrow$ Financial problems & .998 & .081 & .739 & $* * *$ \\
\hline Financial problems - item 5 & $\leftarrow$ Financial problems & 1.188 & .074 & .874 & $* * *$ \\
\hline
\end{tabular}

Source: NELLS 2009, own calculations. ***: $\mathrm{p}<.001$.

Entries are the result of a SEM analysis in MPLUS. Reported are the unstandardized regression weights (B), standard errors (S.E.), standardized regression weights $(\beta)$ and P-values.

${ }^{\mathrm{a}}$ : Parameter constrained to 1.000 to identify the model. 
Table A.3: Residual variances for final model

\begin{tabular}{|c|c|c|c|}
\hline & Est. & S.E. & $\mathbf{P}$ \\
\hline \multicolumn{4}{|l|}{ Structural part } \\
\hline Generalized trust & .243 & .023 & $* * *$ \\
\hline Political trust & .208 & .013 & $* * *$ \\
\hline Cognitive ability & .300 & .039 & $* * *$ \\
\hline Occupational prestige & 160.577 & 5.222 & $* * *$ \\
\hline Financial problems & .535 & .051 & $* * *$ \\
\hline \multicolumn{4}{|l|}{ Measurement part } \\
\hline Generalized trust - item 1 & .401 & .019 & $* * *$ \\
\hline Generalized trust - item 2 & .501 & .023 & $* * *$ \\
\hline Generalized trust - item 3 & .261 & .020 & $* * *$ \\
\hline Political trust - item 1 & .147 & .008 & $* * *$ \\
\hline Political trust - item 2 & .098 & .008 & $* * *$ \\
\hline Political trust - item 3 & .258 & .010 & $* * *$ \\
\hline Political trust - item 4 & .277 & .011 & $* * *$ \\
\hline Linguistic ability - item 1 & .649 & & \\
\hline Linguistic ability - item 2 & .498 & & \\
\hline Linguistic ability - item 3 & .582 & & \\
\hline Linguistic ability - item 4 & .538 & & \\
\hline Linguistic ability - item 5 & .911 & & \\
\hline Linguistic ability - item 6 & .588 & & \\
\hline Linguistic ability - item 7 & .342 & & \\
\hline Linguistic ability - item 8 & .795 & & \\
\hline Linguistic ability - item 9 & .683 & & \\
\hline Mathematical ability - item 1 & .446 & & \\
\hline Mathematical ability - item 2 & .608 & & \\
\hline Mathematical ability - item 3 & .214 & & \\
\hline Mathematical ability - item 4 & .513 & & \\
\hline Mathematical ability - item 5 & .408 & & \\
\hline Linguistic ability & .052 & .031 & .097 \\
\hline Mathematical ability & .386 & .034 & $* * *$ \\
\hline Financial problems - item 1 & .465 & & \\
\hline Financial problems - item 2 & .417 & & \\
\hline Financial problems - item 3 & .184 & & \\
\hline Financial problems - item 4 & .467 & & \\
\hline Financial problems - item 5 & .245 & & \\
\hline
\end{tabular}


$\underline{\text { Note: Tables A. } 4 \text { and A.5 available upon request or in online appendix }}$

Table A.4: R-squares for final model

\begin{tabular}{|c|c|}
\hline & $\mathbf{R}^{2}$ \\
\hline \multicolumn{2}{|l|}{ Structural part } \\
\hline Generalized Trust & .271 \\
\hline Political Trust & .212 \\
\hline Cognitive ability & .363 \\
\hline Occupational prestige & .219 \\
\hline Financial problems & .051 \\
\hline \multicolumn{2}{|l|}{ Measurement part } \\
\hline Generalized trust - item 1 & .454 \\
\hline Generalized trust - item 2 & .405 \\
\hline Generalized trust - item 3 & .613 \\
\hline Political trust - item 1 & .642 \\
\hline Political trust - item 2 & .778 \\
\hline Political trust - item 3 & .423 \\
\hline Political trust - item 4 & .428 \\
\hline Linguistic ability - item 1 & .446 \\
\hline Linguistic ability - item 2 & .600 \\
\hline Linguistic ability - item 3 & .516 \\
\hline Linguistic ability - item 4 & .560 \\
\hline Linguistic ability - item 5 & .127 \\
\hline Linguistic ability - item 6 & .510 \\
\hline Linguistic ability - item 7 & .741 \\
\hline Linguistic ability - item 8 & .277 \\
\hline Linguistic ability - item 9 & .408 \\
\hline Mathematical ability - item 1 & .593 \\
\hline Mathematical ability - item 2 & .430 \\
\hline Mathematical ability - item 3 & .812 \\
\hline Mathematical ability - item 4 & .527 \\
\hline Mathematical ability - item 5 & .630 \\
\hline Linguistic ability & .901 \\
\hline Mathematical ability & .406 \\
\hline Financial problems - item 1 & .548 \\
\hline Financial problems - item 2 & .596 \\
\hline Financial problems - item 3 & .824 \\
\hline Financial problems - item 4 & .546 \\
\hline Financial problems - item 5 & .765 \\
\hline
\end{tabular}

Source: NELLS 2009, own calculations. N=1931. 
Table A.5: Intercepts and thresholds for final model

\begin{tabular}{lrrr}
\hline & Est. & S.E. & P \\
\hline Intercepts & & & \\
Generalized trust - item 1 & .699 & .119 & $* * *$ \\
Generalized trust - item 2 & .368 & .130 & .005 \\
Generalized trust - item 3 & 1.167 & .109 & $* * *$ \\
Political trust - item 1 & .499 & .088 & $* * *$ \\
Political trust - item 2 & .370 & .093 & $* * *$ \\
Political trust - item 3 & 1.008 & .090 & $* * *$ \\
Political trust - item 4 & .497 & .096 & $* * *$ \\
Occupational prestige & 30.961 & 2.275 & $* * *$ \\
Thresholds & & & \\
Linguistic ability - item 1 & 1.766 & .194 & $* * *$ \\
Linguistic ability - item 2 & .869 & .246 & $* * *$ \\
Linguistic ability - item 3 & 2.201 & .227 & $* * *$ \\
Linguistic ability - item 4 & .165 & .247 & .504 \\
Linguistic ability - item 5 & .714 & .192 & $* * *$ \\
Linguistic ability - item 6 & 1.968 & .210 & $* * *$ \\
Linguistic ability - item 7 & 1.211 & .262 & $* * *$ \\
Linguistic ability - item 8 & 1.469 & .191 & $* * *$ \\
Linguistic ability - item 9 & 2.457 & .207 & $* * *$ \\
Mathematical ability - item 1 & .139 & .201 & .488 \\
Mathematical ability - item 2 & .685 & .183 & $* * *$ \\
Mathematical ability - item 3 & .677 & .197 & .001 \\
Mathematical ability - item 4 & .554 & .190 & .004 \\
Mathematical ability - item 5 & .012 & .233 & .960 \\
Financial problems - item 1 & .938 & .232 & $* * *$ \\
Financial problems - item 2 & .346 & .237 & .144 \\
Financial problems - item 3 & .635 & .284 & .025 \\
Financial problems - item 4 & .047 & .344 & .892 \\
Financial problems - item 5 & -.224 & .205 & .273 \\
\hline Source: NEL S 2009, own calculations . N=1931 $* * * . p<.001$ \\
\hline
\end{tabular}




\section{Endnotes}

1. Including ethnic minorities in the analysis, however, did not change the results, but slightly diminished the robustness of the model.

${ }^{2}$. Including students in the model did not change the results, but the model was slightly less robust.

3 . Including the unemployed did lead to exactly the same results.

${ }^{4}$. If we enter linguistic and mathematical ability separately in the model, one can observe that both have basically the same relations with the dependent variables, but with some slight differences. The overall fit of the model is however weaker than if we enter the second order factor.

${ }^{5}$. We have the r-squares (Table A.4) and the intercepts and thresholds (Table A.5) for our final model available upon request. 